\title{
Editorial
}

\section{Bicentenario de la Independencia de Centroamerica}

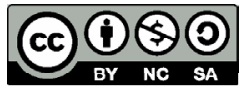

Copyright $\odot 2021$ UNAN-Managua Todos los Derechos Reservados.

Jossarys Massielle Gazo Robles

Antropóloga Social, Docente Investigadora

Departamento de Antropología

Facultad de Humanidades y Ciencias Juridicas

Universidad Nacional Autónoma de Nicaragua, UNAN-Managua

ID Orcid: https://orcid.org/0000-0002-0989-4827

jgazo@unan.edu.ni

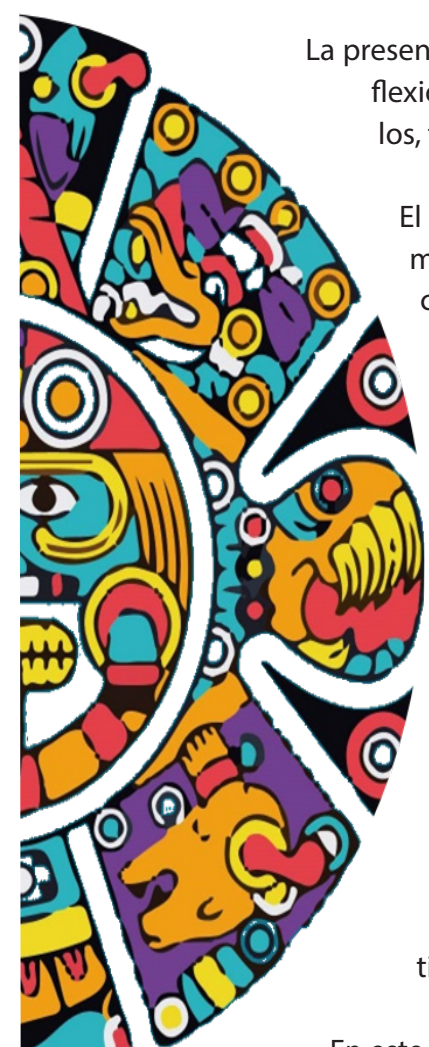

El 15 de septiembre de 2021, el Bicentenario de la Independencia de Centroamérica conmemora los 200 años de la firma del Acta de Independencia, un documento mediante el cual se proclamó el 15 de septiembre de 1821 la separación de la Monarquía Española. Nicaragua, Costa Rica, El Salvador, Guatemala y Honduras, decidieron dar el primer paso hacia la independencia, acto que representó una transición histórica de los pueblos, el nacimiento de la integración y la solidaridad como partes de una misma patria grande.

El bicentenario encuentra a los países centroamericanos enfrentados a crisis sociales, políticas y migratorias. Según Victoria Dannemann: " el fin de la dependencia política y la formación de las nuevas repúblicas en el siglo XIX significaron un campolítico importante", si miramos la realidad social,cultural, la discriminación y la desigualdad, dependencia económica del extranjero, vemos que no cambió tanto".

Los 200 años de independencia de Centro america, nos invita reflexionar sobre el significado real de "independencia", de qué, para quiénes. Al repasar la historia de Centro America, esta la presencia de Estados Unidos y sus empresas bananeras, "los rasgos de dependencia del norte global no cambiaron, lo que cambió fueron los actores". Desde la perspectiva de la vida diaria no hubo grandes cambios en el sentido de que se mantiene la lucha por sobrevivir, combatir la pobreza, la desigualdad".

En este sentido las voces nacionales que dialogan en esta edicion especial de la Revista, crean un discurso de identidad, adaptabilidad, rescate y reflexion. 